\title{
Experimental Study Regarding the Cavitation and Corrosion Resistance of Stellite 6 and Self-Fluxing Remelted Coatings
}

\author{
Costel-Relu Ciubotariu1, ${ }^{*}$ - Evelina Secosan ${ }^{1}$ - Gabriela Marginean ${ }^{2}-$ \\ Doina Frunzaverde ${ }^{1}-$ Viorel Constantin Campian ${ }^{1}$ \\ ${ }^{1}$ University Eftimie-Murgu, Faculty of Engineering and Management, Romania \\ 2 Westfälische Hochschule Gelsenkirchen, Germany
}

This paper aims to compare cobalt-based (type Stellite 6) and nickel-based self-fluxing alloys (type NiCrBSiMo) regarding both their cavitation erosion resistance and corrosion resistance. The two types of protective layers were thermally sprayed onto a substrate of martensitic stainless steel. In order to improve the layers' characteristics and their metallurgical bonding to the substrate, the Stellite 6 coating was laser remelted, while the NiCrBSiMo coating was treated by flame fusion. The cavitation erosion resistance of the two materials was evaluated by measurements of the mean depth of erosion developed during a testing period of 165 minutes, using a $20 \mathrm{kHz}$ ultrasonic vibrator at a peak-to-peak amplitude of $50 \mu \mathrm{m}$. In addition, the corrosion resistance of the layers was assessed by potentiodynamic corrosion tests carried out in $\mathrm{H}_{2} \mathrm{SO}_{4}+\mathrm{NaCl}$ solution at room temperature, using calomel as reference electrode. In order to highlight the differences regarding the behaviour of the two protective materials, the authors also carried out microstructural investigations of the layers before and after exposure to cavitation and corrosion. The investigations showed that both types of layers can provide improved protection of the martensitic stainless steel substrate against cavitation, whilst the NiCrBSiMo coating additionally confers significantly increased resistance to corrosion.

Keywords: cavitation, self-fluxing alloys, Stellite 6, corrosion, laser remelting

Highlights

- With the aim to develop new techniques for the improvement of the hydropower components' lifetime, the authors of this paper carried out a comparative study regarding the resistance of Stellite 6 and NiCrBSiMo coatings against both cavitation and corrosion;

- In order to have a clear image of the evolution of the cavitation erosion, the results obtained in the laboratory tests have been processed statistically by carrying out dispersion strips;

- The investigations showed that both types of layers can provide for the martensitic stainless steel, usually used for manufacturing turbine components, improved protection against cavitation, whilst the NiCrBSiMo coating supplementary confers also significant increased resistance to corrosion.

\section{INTRODUCTION}

Hydropower is a renewable source of energy, nonpolluting and probably the oldest source, which transforms the potential energy of water into mechanical energy by means of hydraulic turbines [1]. Hydropower quality is dependent on the durability and reliability of the hydraulic machinery. Surface damages caused by fatigue, corrosion and wear, in particular cavitation erosion, are among the main causes that lead to the failure of hydropower plant components.

Cavitation is a phenomenon caused by the formation of vapour bubbles in low-pressure regions, followed by their collapse in high-pressure regions [2]. As a result, the metallic surfaces in the vicinity are subjected to erosive wear [3] and [4]. In some cases, cavitation pitting is also accompanied by corrosion damage. Usually, hydraulic components are cast from soft martensitic stainless steels, which contain a small amount of ferrite, assuring an excellent resistance to cavitation erosion. Nevertheless, cavitation erosion cannot be completely avoided and improper material quality or inadequate repair techniques applied in situ sometimes lead to significant material loss and even failure of the hydraulic components due to cavitation [5].

Cavitation in hydro turbines is difficult to avoid completely, but it can be reduced to an economically acceptable level. Several experimental research [6] to [8] and analytical studies [9] to [11] investigate the process of cavitation and its consequences in hydro turbines.

In spite of design changes of the turbine components and the use of high quality stainless steels [12] and [13] or protective coatings [14] to [16], in the case of some applications, the level of cavitation erosion remains unacceptable; consequently, specialists continue to search for solutions. Some studies regarding the investigation of these protective coatings in environments containing a mixture of sulfuric acid with different oxidizing or reducing 
impurities, such as chlorides, have been reported by some authors [17] and [18]. Therefore, the corrosion resistance of the present coatings was considered as well for this work. In this study, two types of thermally sprayed and subsequently remelted protective coatings were investigated regarding their microstructure and cavitation and corrosion resistance.

The results were compared to those obtained on the martensitic stainless steel (type 13-4) commonly used as base material for manufacturing of hydraulic turbine components.

\section{EXPERIMENTAL PROCEDURE}

\subsection{Materials and Processes}

The two protective coatings investigated in this study were deposited on martensitic stainless steel type $1.4313(0.03 \% \mathrm{C}, \quad 12.6 \% \mathrm{Cr}, \quad 3.63 \% \mathrm{Ni}, \quad 0.46 \% \mathrm{Si}$ and $0.71 \% \mathrm{Mn}$ ) using a DJH 2700 high-velocity oxyfuel (HVOF) spraying equipment. Table 1 presents the chemical composition and the particle size of the powders used, the thickness of the deposited cobaltbased alloy (Stellite 6) and the nickel-based selffluxing (NiCrBSiMo) coating.

Prior to spraying, a sand-blasting machine was used to roughen the working surface of the stainless steel substrate to enhance the coating/substrate adhesion. The coatings deposited by thermal spraying usually present a mixture of lamellar-melted and halfmelted or non-melted particles, a certain content of oxides and/or internal porosity. In order to refine the structure and to improve the layers' adhesion to the substrate, the Stellite 6 (St6) coating was remelted by laser treatment [19], whereas the self-fluxing alloy (SF) was subsequently fused using an oxy-fuel torch.

After spraying and remelting, the coatings were examined in cross-section with a scanning electron microscope (SEM/Philips XL30 ESEM), combined with energy dispersive X-ray analysis (EDX/Company) at magnifications between $80 \times$ and $500 \times$, in order to characterize the microstructure, the quality of the interface coating/substrate and the thickness of the deposited layers. In addition, the phase composition was determined by means of X-ray diffractometry (Philipy X'Pert). The cavitation erosion and corrosion resistance of these coatings was evaluated in comparison with that of the martensitic substrate.

\subsection{Cavitation Erosion Test}

The cavitation erosion resistance of the samples was determined in deionized water under laboratory conditions using the vibratory method standardized by ASTM G-32 [20]. The vibration-induced pressure fluctuations were adapted to induce cavitation erosion. The vibration is transmitted by a booster (mechanical transformer of vibration) and a horn to the test specimen, which is immersed in liquid.

The cavitation equipment used in the Center for Research in Hydraulics, Automation and Thermal Processes of the Eftimie Murgu University of Resita uses an ultrasonic device and a piezoelectric converter to generate vibrations at the frequency of $20 \mathrm{kHz}$ and the peak-to-peak amplitude of $50 \mu \mathrm{m}$. The testing period was 165 minutes; the water temperature was maintained at a constant value $\left(25 \pm 2^{\circ} \mathrm{C}\right)$ with a circulatory system, and the mass loss was measured with an electronic balance at a resolution of $10^{-5} \mathrm{~g}$. In order to compare materials with different densities, a volume parameter, the mean depth of erosion (MDE), has been used. In the case of the direct method, the vibratory device generates oscillations on a test specimen that is attached at the horn (by a thread) and submerged in liquid at a certain depth.

The unit consists of the following components: ultrasonic generator and cavitation stand with piezoelectric converter, booster, sonotrode with the specimen, and cooling bath. Fig. 1 shows the stand of cavitation erosion testing.

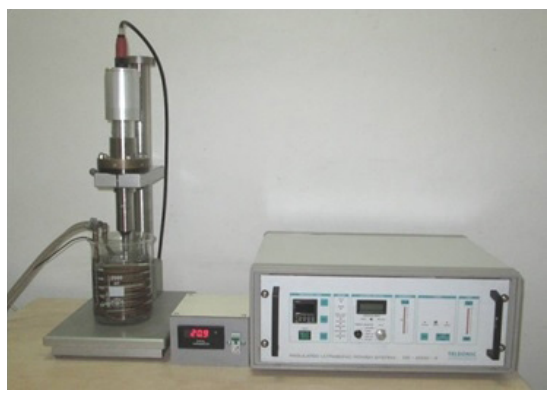

Fig. 1. Stand of cavitation erosion testing

Table 1. Chemical composition and particle size of the feedstock powders, thickness of the sprayed layers

\begin{tabular}{|c|c|c|c|c|c|c|c|c|c|c|}
\hline \multirow{2}{*}{ Powder } & \multicolumn{8}{|c|}{ Composition [\%] } & \multirow{2}{*}{$\begin{array}{c}\text { Particle } \\
\text { size }[\mu \mathrm{m}]\end{array}$} & \multirow{2}{*}{$\begin{array}{c}\text { Layer } \\
\text { thickness }\end{array}$} \\
\hline & $\mathrm{Ni}$ & $\mathrm{Cr}$ & W & C & $\mathrm{Fe}$ & $\mathrm{Si}$ & $B$ & Mo & & \\
\hline Stellite 6 (Co alloy) & 3.26 & 27 to 32 & 4 to 6 & 0.9 to 1.4 & 2.26 & - & - & 4 to 6 & $-45 / 15$ & $468 \mu \mathrm{m}$ \\
\hline Self-fluxing (NiCrBSiMo) & base & 16.5 & - & 0.55 & 3 & 4.5 & 3.8 & 5 & $-106 / 45$ & $1.04 \mathrm{~mm}$ \\
\hline
\end{tabular}




\subsection{Corrosion test}

The corrosion behaviour was evaluated using potentiodynamic polarization tests that were conducted with a potentiostat/galvanostat and a three-electrode cell (Voltalab) in the presence of $0.5 \mathrm{M} \mathrm{H}_{2} \mathrm{SO}_{4}+3.5 \% \mathrm{NaCl}$ solution at room temperature. A platinum wire, a saturated calomel electrode (SCE), and polished specimens were used as the counter electrode, reference electrode, and working electrode respectively.

Potentiodynamic polarization curves were measured from $-1000 \mathrm{mV}$ to $1500 \mathrm{mV}$ at a sweep rate of $5 \mathrm{mV} / \mathrm{min}$ and a room temperature of approximately $20^{\circ} \mathrm{C}$.

\section{RESULTS AND DISCUSSIONS}

\subsection{Microstructure}

The SEM micrographs of the HVOF-sprayed St6 coating presented in Fig. 2 show a relatively homogeneous structure at lower magnitude (Fig.
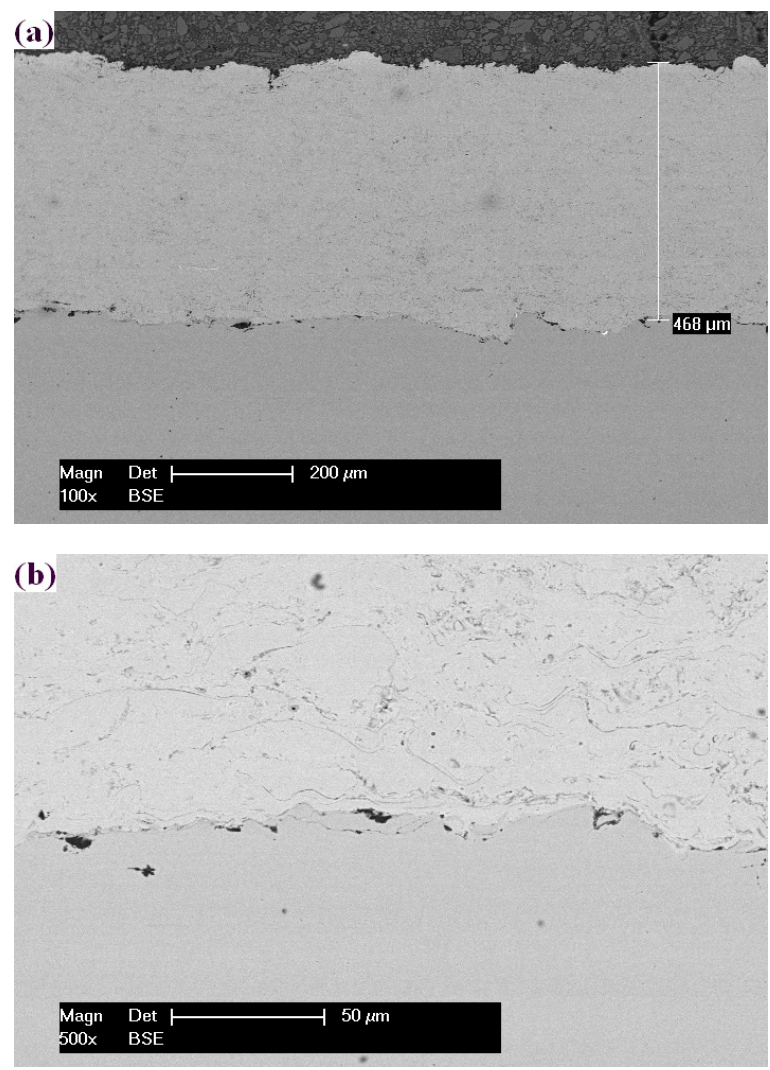

Fig. 2. Cross-section SEM micrographs of as-sprayed St6 coating: a) $100 x$; b) $500 x$ 2a). A further investigation of this coating at higher magnitude $(500 \times)$ reveals the presence of some dark grey inhomogeneities with irregular shapes. EDX analysis performed on these dark grey formations revealed (beside $\mathrm{Co}$ ) a high amount of $\mathrm{Cr}, \mathrm{Si}$, and $\mathrm{O}$ (see Fig. 3). Moreover, even though the degree of adhesion seems to exhibit a good quality for the HVOF-sprayed coating, there are still many impurities along the interface coating/substrate (see Fig. 2b).

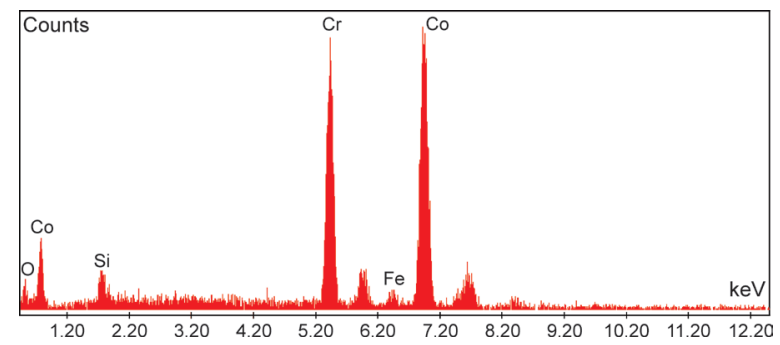

Fig. 3. EDX-spectrum of the dark grey strings visible in the assprayed St6 coating
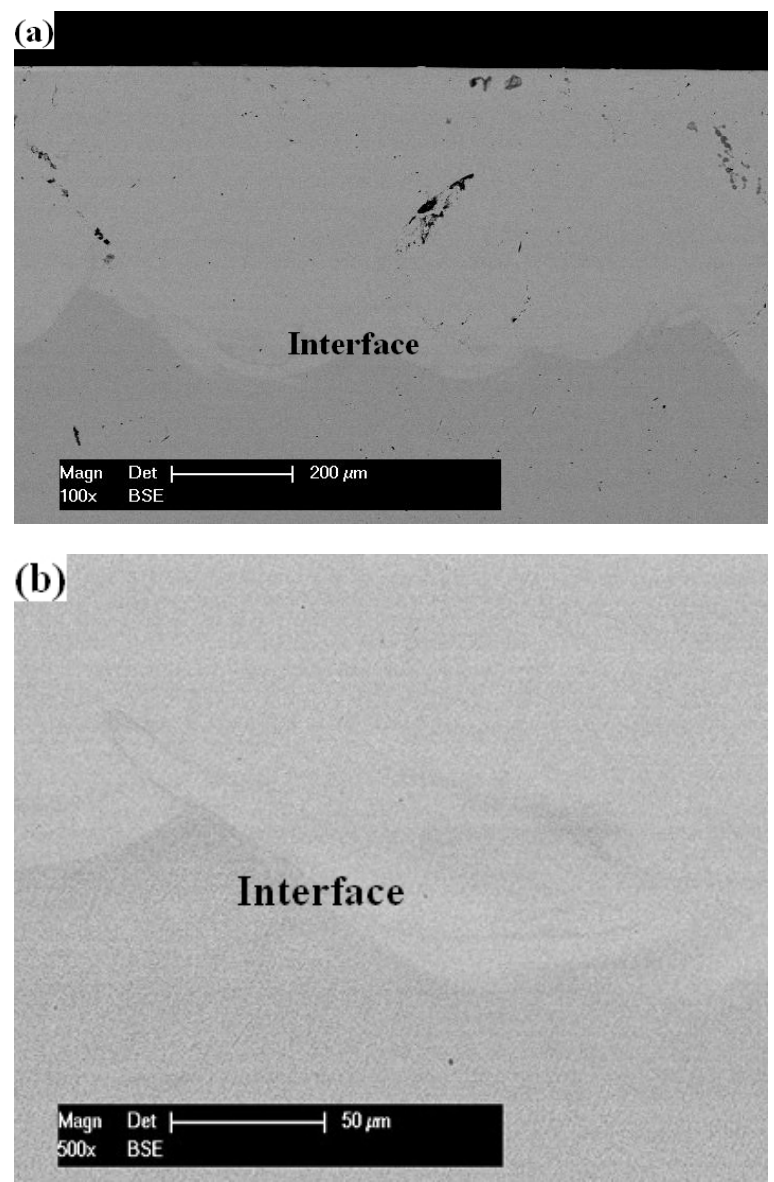

Fig. 4. Cross-section SEM micrographs of laser remelted St6 coating/substrate interface; a) lower magnitude and b) higher magnitude 
Remelting the St6 coating via laser treatment led to a refinement of the microstructure. Cross-section SEM-micrographs of the remelted coating show a very high degree of homogeneity and purity. The internal porosity was eliminated, and the coating/ substrate interface exhibited a clean structure without cracks or inclusions as can be seen in Fig. 4 .

XRD investigations of the laser remelted coating revealed (beside $\mathrm{Cr}$ and Co phases) a high amount of intermetallic compound with a quite low $\mathrm{W}$ content (type $\mathrm{Co}_{0.9} \mathrm{~W}_{0.1}$; see Fig. 5). Moreover, a small amount of another $\mathrm{Co} / \mathrm{W}$ phase was detected, with another ratio between the elements $\left(\mathrm{Co}_{3} \mathrm{~W}\right)$. The XRD data for St6 matches with the ICDD reference patterns: $\mathrm{Co}_{0.9} \mathrm{~W}_{0.1}$ (03-065-9928); $\mathrm{Co}_{3} \mathrm{~W}$ (01-071-7505); Co (00-001-1277); Cr (00-019-0323).

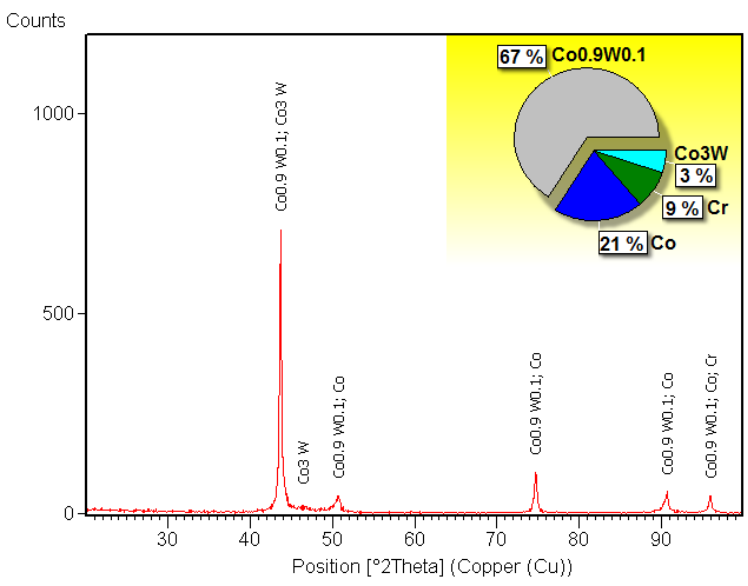

Fig. 5. X-ray diffraction pattern of the laser remelted St6 coating

The cross-section SEM-micrographs of the flame sprayed NiCrBSiMo coating presented in Fig. 6 exhibit a poor adhesion to the substrate with many oxides and micro cracks. At higher magnitude, there is obviously that the degree of interconnection respectively adhesion between two adjacent particles is very low. Much porosity and even some nonmelted particles are clearly observed (Fig. 6b). The microstructure of this coating was substantially refined after the fusing process. The degree of internal porosity was considerably reduced, and the adhesion to the substrate was improved as well (see Fig. 7). In order to identify various structural constituents to emphasize the microstructure of the fused coating some EDX measurements were performed along the coating in cross-section.

The results obtained from the EDX analysis, which were compared with the XRD-pattern of this coating, lead to the conclusion that the light grey constituent with a dendritic structure is composed of a

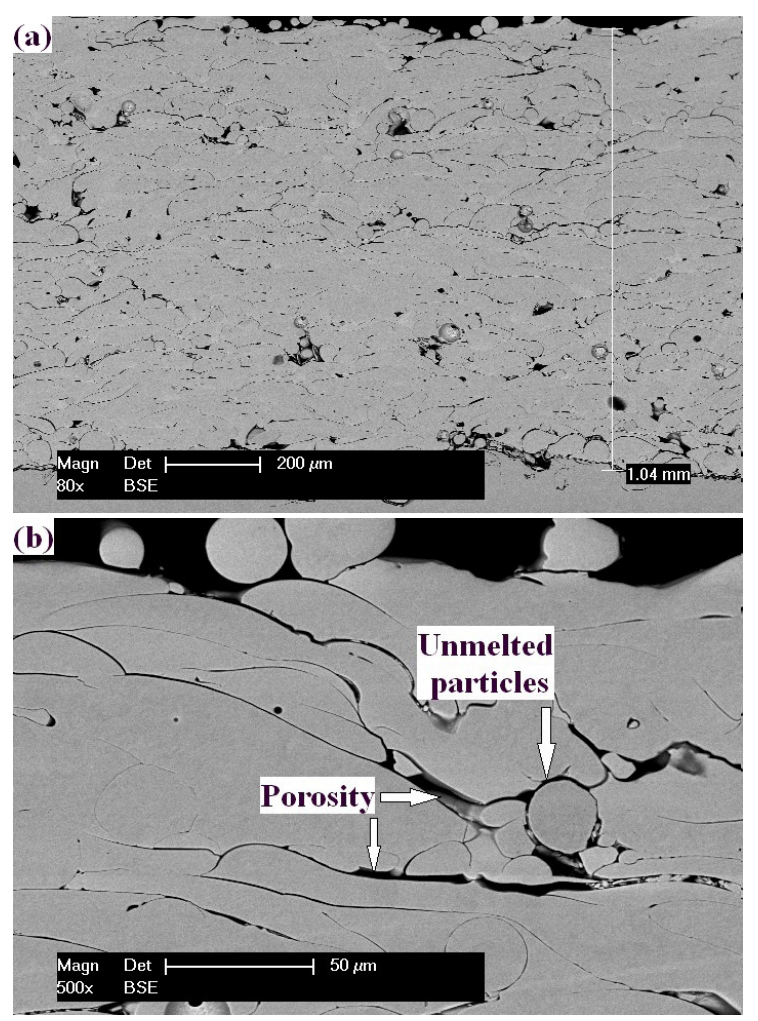

Fig. 6. SEM micrographs of the as-sprayed NiCrBSiMo coating in cross-section; a) lower magnitude and b) higher magnitude
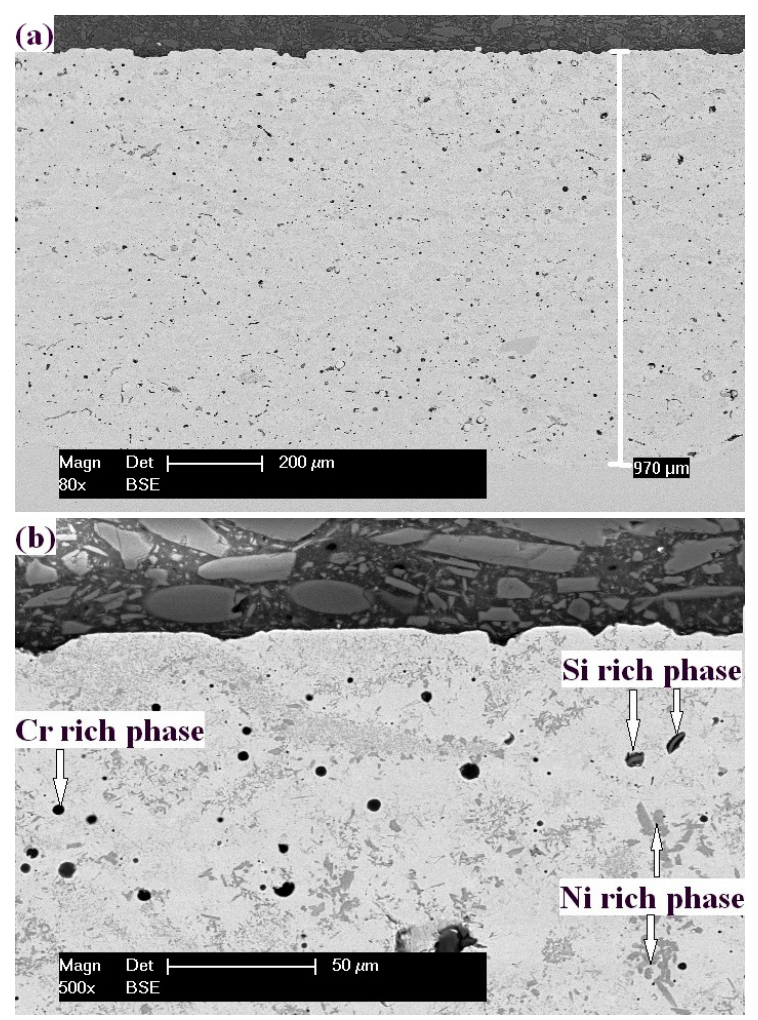

Fig. 7. Cross-section SEM micrographs of the NiCrBSiMo fused coating; a) magnitude 80x and b) magnitude 500x 
nickel-rich phase, probably $\mathrm{Ni}_{3} \mathrm{~B}$ (see Fig. 8a). In Fig. $8 \mathrm{c}$, the black globular formations in the layer consist of a $\mathrm{Cr}$-rich phase $\left(\mathrm{Cr}_{2} \mathrm{O}_{3}\right.$ or $\left.\mathrm{CrB}\right)$. Some constituents with irregular shapes, which exhibit a combination of dark grey to light grey, comprise a Si-rich phase, possibly surrounded by oxides (see Fig. 8b). The XRD-pattern of the fused NiCrBSiMo coating (Fig. 9) shows (beside the $\mathrm{Ni} / \mathrm{CrNi}_{3}$ signal $\gamma^{\prime}-\mathrm{CrNi}_{3}$ phase fine dispersed into the $\gamma$-Ni matrix) also $\mathrm{Ni}$ and $\mathrm{Cr}$ borides as well as iron silicide's. The ICDD reference patterns for the self-fluxing alloy are: $\mathrm{CrNi}_{3}(01-071-7595) ; \mathrm{Fe}$
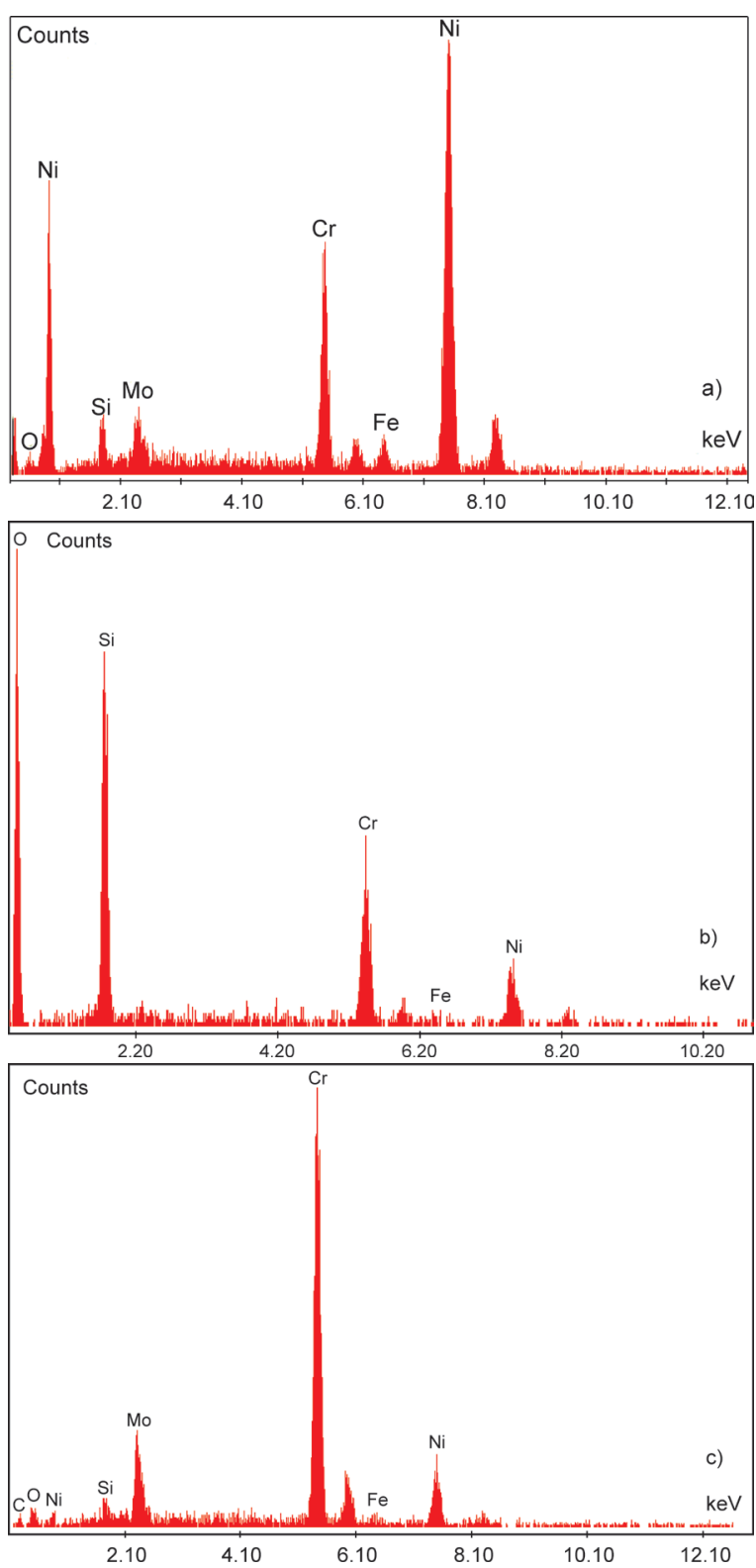

Fig. 8. EDX-spectrum of the fused NiCrBSiMo coating;

a) nickel phase, b) silicon phase, and c) chromium phase
(00-050-1275); $\mathrm{Fe}_{\mathrm{Si}} \mathrm{Si}_{3}(01-074-4744)$; $\mathrm{Ni}_{3} \mathrm{~B}$ (01-0821699); CrB (01-075-1159).

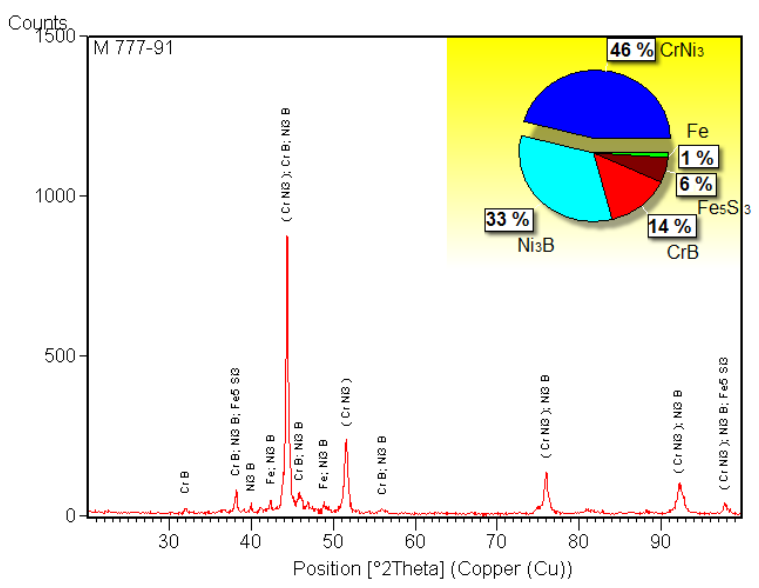

Fig. 9. X-ray diffraction pattern of the fused NiCrBSiMo coating

\subsection{Cavitation Erosion Resistance}

The primary result of an erosion test is the cumulative mass loss. Although, in terms of mass loss versus time, the raw data are for analysis and reporting purposes, this should be converted to a "mean depth of erosion" (MDE) versus time curve, since a volumetric loss is more significant than a mass loss when materials of different densities are compared. Calculate the mean depth of erosion, for the purpose of this test method in conformity with ASTM G-32 [20], with Eq. (1):

$$
M D E=\frac{10^{6} \cdot \Delta m}{\rho \cdot A_{e}},
$$

where the following abbreviations have been used: $\Delta m[\mathrm{mg}]$ mass variation; $A_{e}\left[\mathrm{~mm}^{2}\right]$ area of the eroded surface; $\rho\left[\mathrm{kg} / \mathrm{m}^{3}\right]$ density of the coating exposed to erosion.

Characteristic curves of the mean depth of erosion for the investigated coatings are presented in comparison with that of the martensitic stainless steel substrate, which were tested in the same system (see Fig. 10).

It is noted that both coatings exhibited lower values of the MDE in comparison with the base material. Furthermore, the stabilization rate (Vs) of the cavitation erosion of the two protective layers is lower (values for the MDE and Vs of the tested samples are presented in Table 2). The incubation period for all surfaces tested was: Martensitic stainless steel to 30 minutes; Co base alloy to 70 minutes and Self-fluxing alloy to 45 minutes. 
In order to have a clear image of the evolution of the cavitation erosion, the results obtained in the laboratory tests have been processed statistically by carrying out dispersion strips (see Fig. 11) which result from the estimated error and the polynomial regression curve of the $2^{\text {nd }}$ degree. These bands resulted from using the average values of the cumulative mass losses (CML) for the three samples.

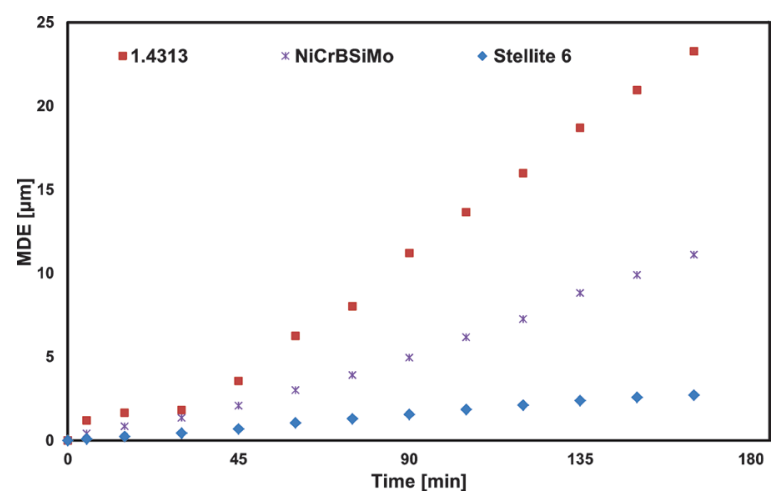

Fig. 10. Mean depth of erosion against time of cavitation attack for the tested materials (Martensitic stainless steel, self-fluxing alloy, and Co-based alloy)

Table 2. Values for mean depth of erosion to 165 minutes and stabilization rate $\left(V_{s}\right)$ for all tested surfaces

\begin{tabular}{lccc}
\hline Measurements & 1.4313 & NiCrBSiMo & St6 \\
\hline MDE $[\mu \mathrm{m}]$ & 23.27 & 11.10 & 2.70 \\
\hline$V_{s}\left[\mathrm{~mm}^{3} / \mathrm{min}\right] \times 10^{-2}$ & 3.12 & 1.62 & 0.18 \\
\hline
\end{tabular}

The approximated values for the curves shown in Figs. 11a to $11 \mathrm{c}$ were obtained based on the experimental measurements for each material type. The values for the tested materials fall within the error ranges specific for each material. The maximum value of the estimated error and the cumulated mass loss value for all surfaces tested are shown in Table 3.

Table 3. Time evolution of the cavitation erosion and experimental values versus statistical values

\begin{tabular}{lccc}
\hline Samples & 1.4313 & NiCrBSiMo & St6 \\
\hline $\begin{array}{l}\text { Experimental cumulative } \\
\text { mass losses [mg] }\end{array}$ & 36.01 & 15.17 & 4.46 \\
\hline $\begin{array}{l}\text { Maximum value of the } \\
\text { estimate error [mg] }\end{array}$ & 37.18 & 15.39 & 4.62 \\
\hline
\end{tabular}

Analysing the results presented in Tables 2 and 3 and in Fig. 10 reveals that in the case of testing by the direct ultrasonic method, the Co-based alloy has the highest resistance to cavitation erosion followed closely by the self-fluxing alloy. In the case of the Cobased alloy sample, the lowest value for cumulated mass losses (4.46 mg) was registered at a mean depth of erosion of $2.7 \mu \mathrm{m}$. Compared with the martensitic stainless steel used as the substrate, the St6 showed a stabilization rate of erosion of approximately 17 times lower. Good resistance to cavitation was alse seen in case of the self-fluxing alloy with the cumulated mass loss of $15.17 \mathrm{mg}$, MDE of $11.10 \mu \mathrm{m}$ and stabilization rate of approximately two times lower than that of the base material.
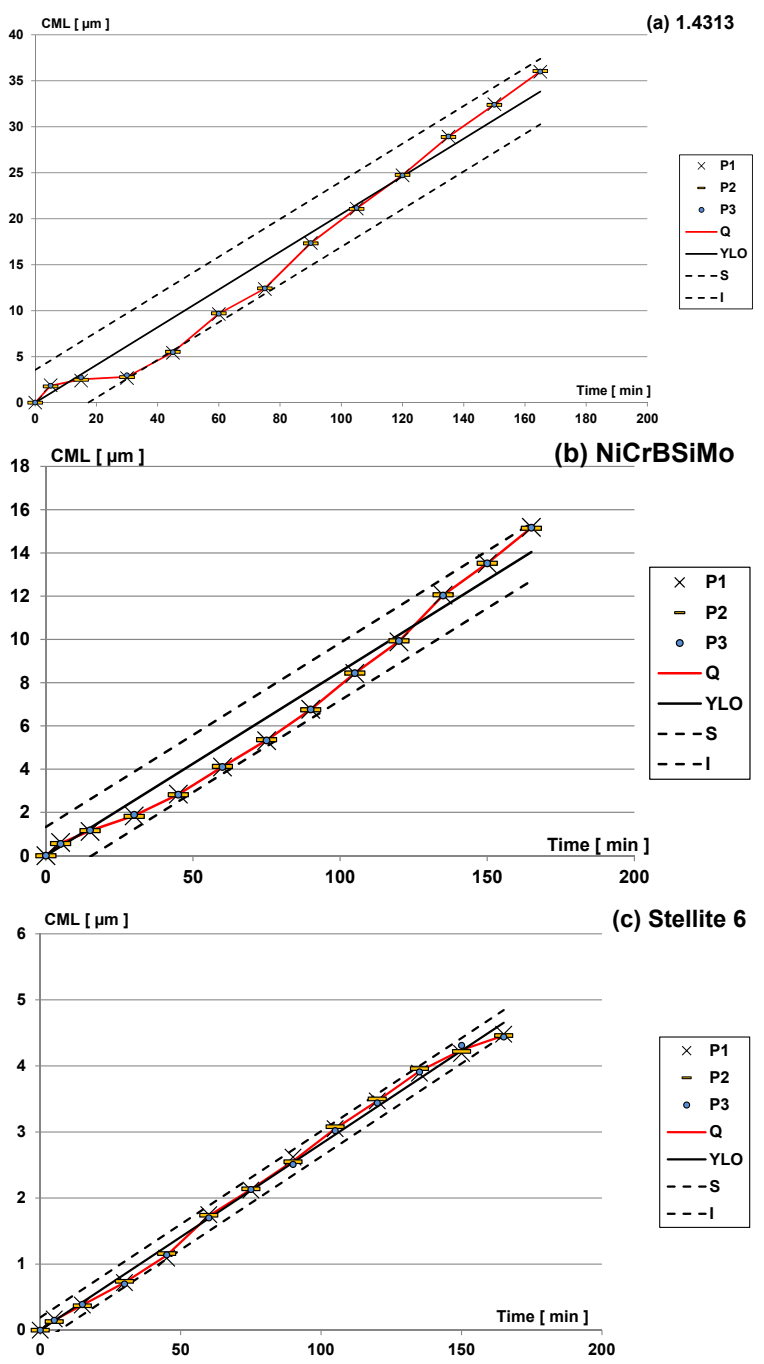

(c) Stellite 6

Fig. 11. The error ranges for all samples tested to cavitation erosion for a) martensitic stainless steel, b) self-fluxing alloy and c) Co-based alloy; P1, P2 and P3 are all three samples tested; $Q$ the average cumulative to mass losses; YLO polynomial regression curve; $S$ upper range value of tolerance and I lower range value of tolerance

Fig. 12 presents SEM-micrographs of the samples before and after the cavitation tests. It can be observed that at the end of the total period of exposure to cavitation the Co-based alloy and the martensitic 

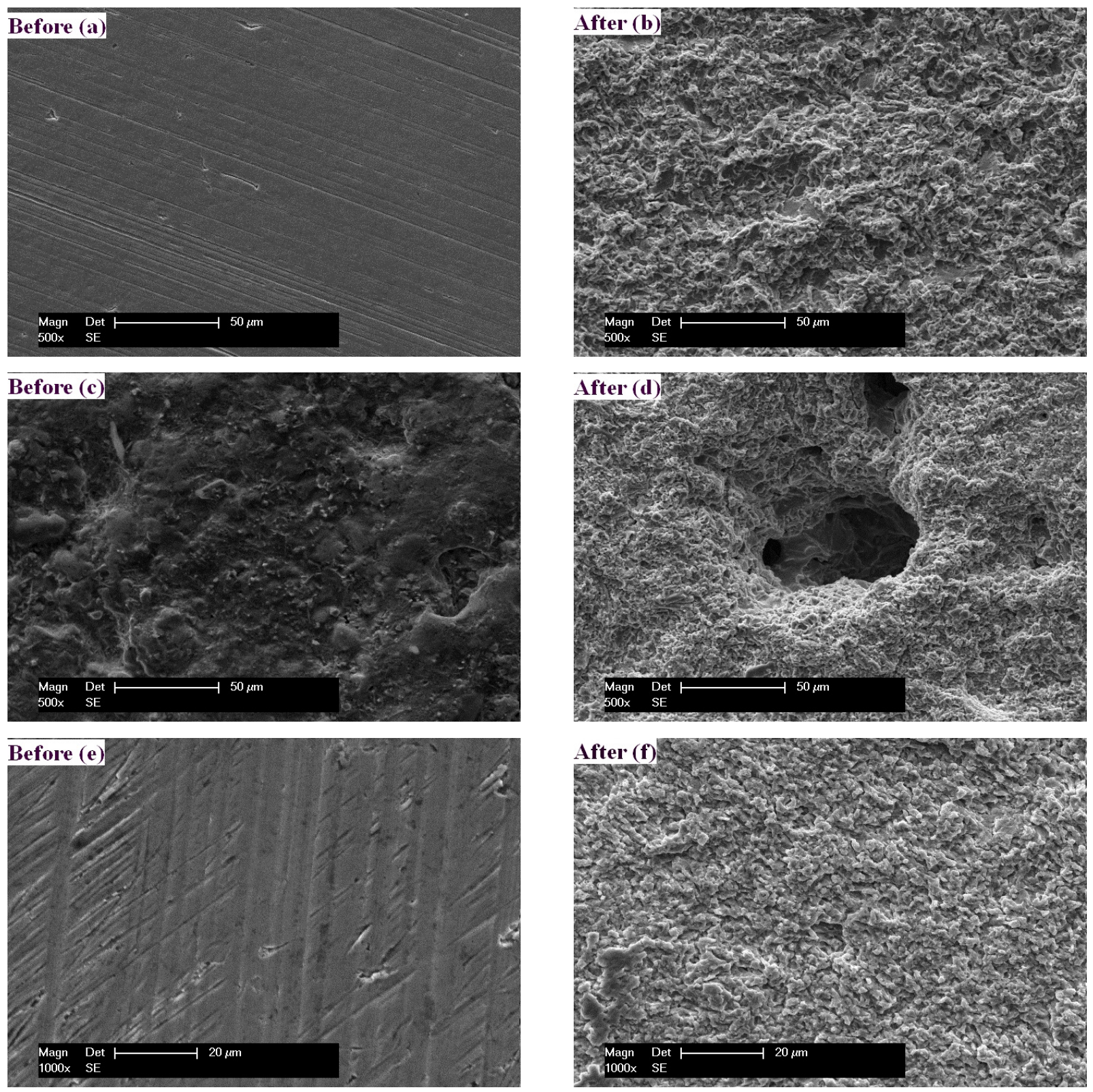

Fig. 12. SEM micrographs of the samples surface before and after cavitation erosion; a) and b) martensitic stainless steel; c) and d) self-fluxing alloy; e) and f) Co-based alloy

stainless steel show a uniform degradation of the entire surface, whereas the surface of the self-fluxing alloy exhibited material spallation in the form of crippling caverns specific for cavitation erosion.

\subsection{Corrosion Resistance}

From the polarization curves of the tested materials, it can be seen that significant modification in the corrosion resistance of the sample surfaces occurred.
This can be observed by comparing the values for the corrosion potential $\left(U_{c o r r}\right)$ respectively for the corrosion current density $\left(i_{\text {corr }}\right)$ of the three samples. The $i_{\text {corr }}$ values for the investigated coatings are clearly lower than that of the base material. Low values for $i_{c o r r}$ as well as more cathodic potentials for $E_{\text {corr }}$ are indicators for a good corrosion resistance.

This theoretical affirmation leads to the conclusion that the best corrosion resistance was exhibited from the NiCrBSiMo coating followed by 
St6. Although the values for the icorr are quite similar for the tested coatings (see Fig. 13), based on the fact that the corrosion potential of St6 is more anodic, one may conclude that the corrosion resistance of this material is lower than that of the fused self-fluxing alloy.

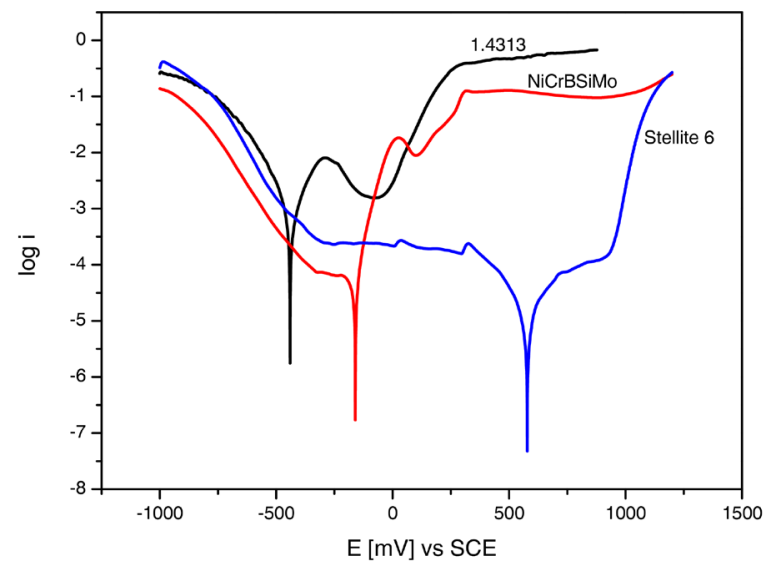

Fig. 13. Polarization curves of the samples tested in a $0.5 \mathrm{M} \mathrm{H}_{2} \mathrm{SO}_{4}+3.5 \% \mathrm{NaCl}$ solution at room temperature
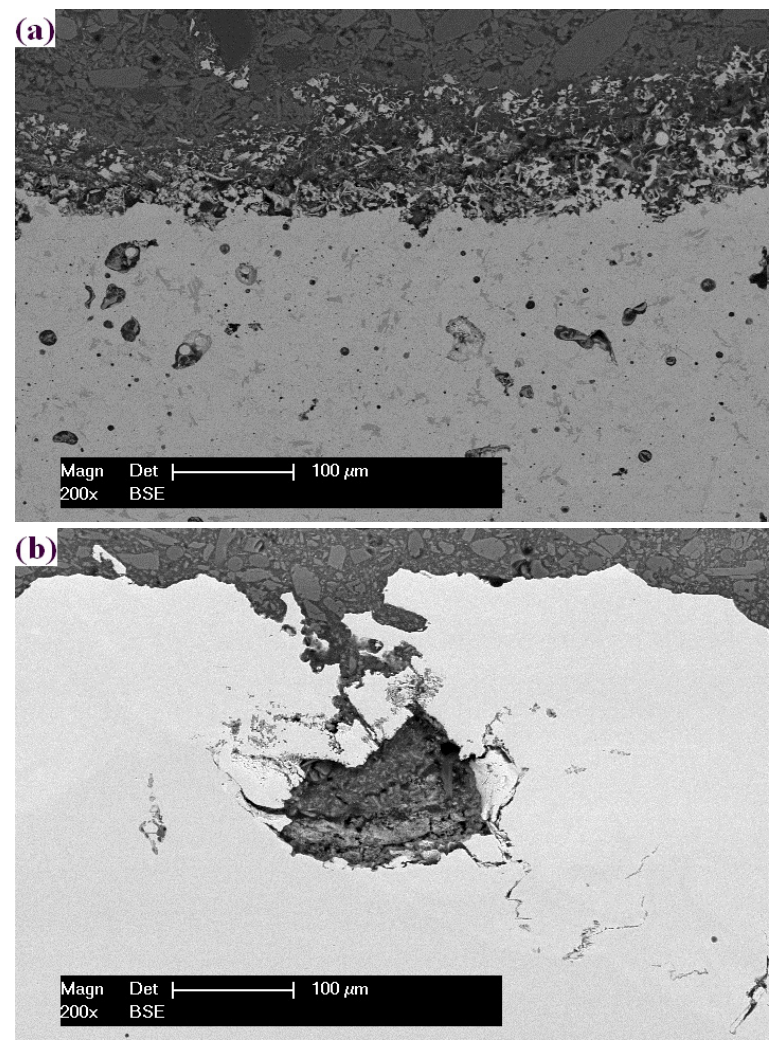

Fig. 14. Cross-section SEM micrographs of the corroded samples; a) NiCrBSiMo coating and b) St6 coating

This observation is confirmed by the SEM micrographs of the corroded coatings in the cross- section that reveal a homogeneous corrosion attack over the entire sample surface in the case of the selffluxing alloy (Fig. 14a), whereas in the case of the St6 coating, a certain degree of localized corrosion attack occurs (pitting attack due to the presence of chlorine ions (Fig. 14b).

\section{CONCLUSIONS}

The results of the performed investigations revealed that the two types of protective layers (St6 and $\mathrm{NiCrBSiMo)}$ assure a considerable improvement of the resistance to cavitation erosion and corrosion compared to that of the soft martensitic stainless steel substrate.

The Co-based alloy exhibited the highest resistance to cavitation erosion during testing by the direct ultrasonic method, while the corrosion resistance, although better than that of the martensitic substrate, should be treated with caution because of the undesirable pitting attack.

In contrast, the NiCrBSiMo coating exhibited excellent corrosion resistance, especially due to the corrosion mechanism, which leads to the uniform corrosion of the surface, combined with an improved cavitation resistance in comparison to that of the martensitic substrate.

Based on the obtained results, it may be concluded that the investigations carried out by the authors show that both types of layers can provide proper protection of the martensitic stainless steel substrate against cavitation, whilst the nickel-based self-fluxing alloy supplementary also confers significantly increased resistance to corrosion.

\section{ACKNOWLEDGMENTS}

The work has been funded by the Sectorial Operational Programme Human Resources Development 20072013 of the Ministry of European Funds through the Financial Agreement POSDRU/159/1.5/S/132395.

\section{REFERENCES}

[1] Tong, D. (1981). Cavitation and wear on hydraulic machines. International Water Power and Dam Construction.

[2] Biluš, I., Bombek, G., Hočevar, M., Širok, B., Cenčič, T., Petkovšek, M. (2014). The experimental analysis of cavitating structure fluctuations and pressure pulsations in the cavitation station. Strojniški vestnik - Journal of Mechanical Engineering, vol. 60, no. 3, p. 147-157, Dol:10.5545/svjme.2013.1462.

[3] Haosheng, C., Jiang, L., Darong, C., Jiadao, W. (2008). Damages on steel surface at the incubation stage of the 
vibration cavitation erosion in water. Wear, vol. 265 , no. 5-6, p. 692-698, D0I:10.1016/j.wear.2007.12.011.

[4] Laguna-Camacho, J.R., Lewis, R., Vite-Torres, M., MendezMendez, J.V. (2013). A study of cavitation erosion on engineering materials. Wear, vol. 301, no. 1-2, p. 467-476, Dol:10.1016/j.wear.2012.11.026.

[5] Frunzaverde, D., Câmpian, C.V., Mărginean, G. (2006). Metallographic investigations on anti-cavitation lips of kaplan blades. Symposium on Hydraulic Machinery and Systems, International Association of Hydraulic Research, Yokohama.

[6] Dular, M., Širok, B., Stoffel, B. (2005). The influence of the gas content of water and the flow velocity on cavitation erosion aggressiveness. Strojniški vestnik - Journal of Mechanical Engineering, vol. 51, no. 3, p. 132-145.

[7] Hattori, S., Takinami, M. (2010). Comparison of cavitation erosion rate with liquid impingement erosion rate. Wear, Vol. 269, no. 3-4, p. 310-316, Dol:10.1016/j.wear.2010.04.020.

[8] Santa, J.F., Blanco, J.A., Giraldo, J.E., Toro, A. (2011). Cavitation erosion of martensitic and austenitic stainless steel welded coatings. Wear, vol. 271, no. 9-10 p. 1445-1453, D0l:10.1016/j.wear.2010.12.081.

[9] Cojocaru, V., Campian, C.V. Miclosina, C.0. (2011). Experimental analysis of residual stresses in samples of austenitic stainless steel welded on martensitic stainless steel used for Kaplan blades repairs. Annals of "Eftimie Murgu" University, vol. 18, no. 1, p. 161-166.

[10] Mostafa, N.H., Mohamed A. (2012). Unsteady numerical simulation of cavitation in axial turbine. CFD Letters, vol. 4, no. 3, p. 140-149.

[11] Muntean, S., Susan-Resiga, R.F., Bernad, S., Ioan, A. (2004). Analysis of the GAMM Francis turbine distributor 3D flow for the operating range and optimization of the guide vane axis location. The $6^{\text {th }}$ International Conference on Hydraulic Machinery and Hydrodynamics, Timisoara, p. 131-136.

[12] Park, M.C., Shin, G.S., Yun, J.Y., Heo, J.H., Kim, D.I., Kim, S.J. (2014). Damage mechanism of cavitation erosion in austenitemartensite phase transformable $\mathrm{Fe}-\mathrm{Cr}-\mathrm{C}-\mathrm{Mn} / \mathrm{Ni}$ alloys. Wear, vol. 310, no. 2, p. 27-32, Dol:10.1016/j.wear.2013.12.015.
[13] Espitia, L.A., Toro, A. (2010). Cavitation resistance, microstructure and surface topography of materials used for hydraulic components. Tribology International, vol. 43, no. 11, p. 2037-2045, DOl:10.1016/j.triboint.2010.05.009.

[14] Cojocaru, V., Frunzaverde, D., Campian, C.V., Marginean, G., Ciubotariu, R., Pittner, A.M. (2010). Cavitation erosion investigations on thermal spray coatings. International Conference Proceedings on Engineering Mechanics, Structures, Engineering Geology, p. 177-180.

[15] Secosan, E.R., Ciubotariu, C.R., Cojocaru, V., Frunzaverde, D., Campian, C.V. (2014). Study regarding the cavitation erosion behavior and residual stresses of impact resistant hardfacing materials. Advanced Materials Research, vol. 1029, p. 146151, D0I:10.4028/www.scientific.net/AMR.1029.146.

[16] Romo, S.A., Santa, J.F., Giraldo, J.E., Toro, A. (2012). Cavitation and high-velocity slurry erosion resistance of welded Stellite 6 alloy. Tribology International, vol. 47, p. 16-24, D0l:10.1016/j. triboint.2011.10.003.

[17] Nickelinstitute (2015). From http://www.nickelinstitute.org/ / Media/Files/TechnicalLiterature/TheCorrosionResistanceof Nickel_ContainingAlloysinSulphuricAcidandRelatedCompoun ds_1318_.pdf, accessed on 2015-10-28.

[18] High-Performance Alloys for Resistance to Aqueous Corrosion (2000). From http://www.google.de/url?sa=t\&rct=j\&q=\&es $r c=s \&$ source $=$ web\& $c d=10 \& v e d=0 C F I Q F j A J a h U K E$ WiP\&YKv 4 c3HAhXCXiwKHRRIBrk\&url=http\%3A\%2F\%2Fwww. parrinst. com\%2Fde\%2Ffiles\%2FParr_Inconel-Incoloy-Monel-NickelCorrosion-Info.pdf\&ei=FV7hVc-SM8K9sQGUypnICw\&usg $=A F Q$ jCNFqeLWaGWyTvn5WUA1FHiRNKNDmHQ, accesed on 201510-28.

[19] Ciubotariu, C.R., Frunzaverde, D., Marginean, G., Serban, V.A., Birdeanu, A.V. (2016). Optimization of the laser remelting process for HVOF-sprayed Stellite6 wear resistant coatings. Optics \& Laser Technology, vol. 77, p. 98-103, D0l:10.1016/j. optlastec.2015.09.005.

[20] ASTM G32 (2010). Standard Test Method for Cavitation Erosion Using Vibratory Apparatus. ASTM International, West Conshohocken. 